Ueber die quantitative Bestimmnng kleiner Mengen Kobalt im Nickel. Von

\title{
Dr. Fleitmann.
}

Die genaue Bestimmung geringer Mengen Kobalt im Nickel bietet wegen der beschränkten Unlöslichkeit des gelben Doppelsalzes mit salpetrigsaurem Kali und wegen des leichten Mitfallens anderer Doppelsalze grosse Schwierigkeiten, und es liefert, sobald es sich um Verhältnisse von weniger als 1 Theil Kobalt auf 100 Theile Nickel handelt, die direkte Fällung mittelst salpetrigsauren Kalis sehr wenig übereinstimmende Resultate.

Um genannte Schwierigkeiten zu vermeiden, wende ich bereits seit etwa 15 Jahren mit grossem Vortheil eine vorherige Abscheidung des Kobalts zusammen mit einem gewissen Theil des Nickels an, wodurch eine Concentration des Kobaltgehalts erzielt wird, die, wie leicht einzusehen, die Genauigkeit der Bestimmung des Kobalts durch salpetrigsaures Kali bedeutend erhöht.

Diese Concentration erreicht man auf sehr leichte Weise durch eine partielle Fällung der vorher neutralisirten salzsauren Lösung des Nickels und Kobalts mittelst einer schwach alkalischen Lösung von unterchlorigsaurem Natron.

Bekanntlich wird aus Nickel und Kobalt enthaltenden Lösungen durch unterchlorigsaure Salze zunächst das Kobalt in der Form von braunem oxydhydrat gefällt und es beginnt erst hierauf bei weiterem Zusatz des Fällungsmittels die Bildung von schwarzem Nickeloxydhydrat.

Man sucht nun zu gedachtem Zwecke die partielle Fällung mittelst unterchlorigsauren Natrons so zu leiten, dass ein Verhältniss von mindestens 2 Theilen Nickel auf 1 Theil Kobalt niedergeschlagen wird und kann dann sicher sein, dass in der zurückbleibenden Nickellösung keine wägbare Spur von Kobalt melr vorhanden ist. Man erkennt das richtige Verhältniss leicht an der Farbe, welche die Lösung des Niederschlags nachher zeigt. Bei einem Verhältniss von 3 Theilen auf 1 'Theil Kobalt ist dieselbe fast farblos; ${ }^{*}$ ) bei mehr Nickel spielt sie in's Grünliche,

*) In vielen Lehrbüchern heisst es irrthümlich, dass die Nickel- und Kobaltsalze in Gemischen 'von gleichen Theilen farblos seien, während 3 Nickel auf 1 Kobalt nahezu farblose Lösungen bilden. Fl. - Vergleiche in dieser Beziehung auch Winkler d. Zeitschr. 5, 425. R. F. 
bei weniger Nickel in's Röthliche. Ist die erhaltene Lösung intensiv roth, so muss man befürchten, dass noch Kobalt in Lösung geblieben, und es ist in diesem Falle eine zweite partielle Fällung anzurathen.

Bei einiger Aufmerksamkeit erkennt man übrigens leicht die boginnende Fällang des Nickeloxydhydrates, theils an der viel schwärzeren Farbe des Niederschlags, theils an der gleichzeitigen stärkeren Entwicklung der Sauerstoffbläschen beim Kochen der Lösung. Unter Beobachtung dieser Anzeichen ist es nach einiger Uebung gar nicht schwierig, sogleich ein richtiges, zweckentsprechendes Verhältniss von Nickel- und Kobaltoxydhydrat auszufällen.

Nach leichtem Auswaschen löst man den so erhaltenen Niederschlag der beiden Oxydhydrate mit warmer Salzsäure vom Filter, beseitigt durch Kochen das überschüssige Chlor und fällt in der Wärme mittelst Kalilauge das Gemisch von Kobaltoxydul und Nickeloxydul aus. Nachdem dasselbe filtrirt und mit Wasser etwas gewaschen, wird es in Essigsäure oder Salpetersäure aufgelöst und damit in gewohnter Weise zur Fällung des Kobalts mittelst salpetrigsauren Kalis verfahren. Das zur partiellen Fällung der Oxydhydrate dienende unterchlorigsaure Natron stellt man sich sehr leicht durch Umsetzung einer starken Chlorkallklösung mit reinem kohlensaurem Natron dar.

Das rom Niederschlag des kohlensauren Kalks abgegossene oder filtrirte anterchlorigsaure Natron enthält in der Regel anfangs noch etwas Kalk und Magnesia, welche Erden sich aber auf Zusatz von einigen Tropfen Natronlange bei längerem Stehen vollständig als kohlensaure Salze abscheiden. Reines unterchlorigsaures Natron ist ausserdem, worauf ich die Analytiker aufmerksam machen möchte, für Oxydationszwecke ein so bequemes Reagens, dass es auf keinem Reagenstisch fehlen sollte.

\section{Ueber Filtration. \\ Von}

Dr. Fleitmann.

Die Theorie des Filtrirens, diese Geduldsprobe der Chemiker, seheint mir nicht so allgemein bekannt zu sein, als sie es sein sollte. Während man in neuerer Zeit das Filtriren durch Anwendung von Druck möglichst zu beschleunigen gesucht hat und Jeder den Einfluss des Druckes 